\title{
AS PERCEPÇÕES DO ENFERMEIRO ACERCA DA INTEGRALIDADE DA ASSISTÊNCIA
}

\author{
THE PERCEPTIONS OF THE NURSE CONCERNING THE COMPLETENESS OF THE ASSISTANCE
}

\section{LAS PERCEPCIÓNES DEL ENFERMERO SOBRE LA INTEGRALIDAD DE LA ASISTENCIA}

\author{
Ilka Chediak Pinho ${ }^{1}$, Josilucy Cristine Brito Aguiar Siqueira ${ }^{2}$, Lícia Maria Oliveira Pinho ${ }^{3}$
}

RESUMO: O presente estudo teve o objetivo de conhecer os significados acerca da integralidade por enfermeiros de Unidades de Saúde da cidade de Goiânia, Goiás. Trata-se de um estudo descritivo com abordagem qualitativa. Por meio das falas das enfermeiras entrevistadas emergiram duas categorias: "Integralidade: entre o conhecer e o aplicar" e "Integralidade: o despreparo para lidar com a subjetividade do outro". O tema que emergiu foi a percepção do enfermeiro acerca da integralidade da assistência. Este tema desvela o relato das enfermeiras que conhecem, desconhecem e/ou confundem o significado de integralidade, aplicando-os ou não em seu cotidiano. O envolvimento e respeito com os usuários, entretanto, revela a precária interação e despreparo para lidar com a dimensão subjetiva nas práticas de atenção por parte de algumas enfermeiras. A integralidade não deve ser transformada em um conceito, mas sim numa prática do cuidado que trata da valorização da vida, do respeito ao outro e das diferenças entre os seres humanos.

PALAVRAS-CHAVE: Cuidados de Enfermagem; Educação em Enfermagem; Assistência Integral à Saúde.

ABSTRACT: This study had as aim to know the meaning of health integrality for nurses of a Primary Health Services in Goiânia, Goiás, by a descriptive study in a qualitative approach. From interviewed nurses speeches two categories has emerged: "Completeness: between knowing and applying" and "Completeness: the unprepared to deal with the subjectivity of the other one". The subject that emerged was nurse's perceptions concerning the completeness of the assistance. This subject show the story of the nurses who know, are unaware of and/or confuse about the completeness meaning, applying them or not to their daily activities. The involvement and respect with the patients, however, reveals the precarious interaction and unprepared to deal with the subjective dimension in the assistance practice. The completeness does not have to be made into a concept, but in health care practice that deals life, respect to the other and differences among human beings valuation.

KEY WORDS: Nursing Care; Nursing Education; Comprehensive Health Care.
RESUMEN: Este estudio tuvo como objetivo, conocer los significados de la integralidad de la salud para los enfermeros de los servicios de atención primaria en salud de la ciudad de Goiania, Goiás, por medio de un estudio descriptivo de abordaje cualitativo. Por medio de los discursos de las enfermeras se emergió las categorías: "Integralidad: entre el conocer e el aplicar" e "Integralidad: el despreparación para tratar con la subjetividad del otro". El tema que emergió fue las percepciones de las enfermeras en relación a integralidad de la asistencia en salud. Este tema revela el relato de las enfermeras que conocen, desconocen o confunden el significado de integralidad, lo utilizando o no en su cotidiano. El envolvimiento e respecto con los usuarios, sin embargo, revela las precarias interacciones y despreparación para ocuparse de la dimensión subjetiva en las prácticas de atención en salud. La integralidad no tiene que ser hecho en un concepto, sino en la práctica del cuidado en salud que trata de la valorización de la vida del respecto al otro y a las diferencias entre los seres humanos.

PALABRAS CLAVE: Atención de Enfermería; Educación en Enfermería; Atención Integral de Salud.

\footnotetext{
${ }^{1}$ Enfermeira. Pedagoga da Secretaria de Educação de Goiânia, Goiás, Brasil. E-mail: ilkacp@hotmail.com

${ }^{2}$ Enfermeira. Goiânia, Goiás, Brasil.

${ }^{3}$ Enfermeira. Mestre em Enfermagem. Doutoranda no Programa Multiinstitucional de Pós Graduação em Ciências da Saúde Convenio Rede Centro Oeste - UnB/UFG/UFMS. Professora-adjunta do Departamento de Enfermagem e Fisioterapia da Universidade Católica de Goiás (UCG). Pesquisadora de Iniciação Científica do NEPSS (BIC - UCG). Goiânia, Goiás, Brasil. E-mail: licia@ucg.br
} 


\section{INTRODUÇÃO}

A integralidade não pode ser definida apenas como uma diretriz básica do SUS, mas pode ser percebida como um conjunto de noções pertinentes a uma assistência livre de reducionismo; com uma visão abrangente do ser humano, tratando não somente como seres doentes, mas como pessoas dotadas de sentimentos, desejos e aflições.

A integralidade sugere a ampliação e o desenvolvimento do cuidar na profissão da saúde, a fim de formar profissionais mais responsáveis pelos resultados das práticas de atenção, mais capazes de acolhimento, de vínculo com os usuários das ações e serviços de saúde e, também, mais sensível às dimensões do processo saúde /doença inscrita nos âmbitos da epidemiologia ou terapêutica.

O enfermeiro como um profissional participante da equipe multi-profissional, deve engajar-se na luta dos valores preconizados pelo SUS, bem como na concretização da integralidade na Rede Básica de Saúde.

Na década de 70, criou-se o Sistema Nacional de Saúde (SNS), onde foi consolidada uma antiga divisão entre as instituições responsáveis pela saúde pública (Ministério da Saúde) e pela assistência médica (Ministério da Previdência Social). Essa fragmentação no sistema de saúde foi criticada, pois se criou um local para formulação de uma política de saúde que promovesse a articulação da assistência e da saúde pública, havendo uma distinção entre a política de saúde pública e a assistência médica.

Segundo MENDES (1999), as políticas de saúde foram caracterizadas no período de 1980-90, por seu desenvolvimento no contexto de uma crise econômica, expressada por meio da deterioração da situação cambial, da aceleração inflacionária, da recessão e, principalmente, da ruptura de um padrão de crescimento apoiado na articulação solidária entre Estado, empresas multinacionais e empresas privadas nacionais.

De acordo com MENDES (1999), a proposta de descentralização surgiu com a criação do SUDS, em 1987. Sendo seus princípios, aqueles incorporados da Reforma Sanitária (1986): universalização, integralidade da atenção, regionalização, hierarquização, descentralização do processo decisório, democratização das instâncias gestoras e políticas integradas de recursos humanos.

O SUDS incorporou conteúdos estratégicos visando realizar os princípios da reforma sanitária e preparar sua transição para o SUS.

Em 1988, foi promulgada a Constituição Federal, a qual definiu saúde como dever do Estado e direito da população e, que as ações e os serviços de saúde são de importância pública e devem ser providos por um
Sistema Único de Saúde (SUS), cujas diretrizes são: descentralização; mando único em cada esfera do governo; atendimento integral; e participação comunitária.

Conforme a Lei Orgânica da Saúde, nº 8.080, de 19 de setembro de 1990 , Título I, Art.3ㅜ, a saúde tem como fatores determinantes e condicionantes, entre outros, a alimentação, a moradia, o saneamento básico, o meio ambiente, o trabalho, a renda, a educação, o transporte, o lazer e o acesso aos bens e serviços essenciais. Os níveis de saúde da população expressam a organização social e econômica do país.

Nos dias atuais, na busca por uma melhor assistência à saúde faz-se necessário o cumprimento das diretrizes e princípios do SUS. Particularmente do atendimento integral ao paciente, tendo em vista sua implicação numa prática de qualidade, que desenvolva capacidade de análise crítica de contextos. A ação integral pressupõe mudanças nas relações de poder entre os profissionais de saúde e, entre o profissional de saúde e o usuário.

O SUS preconiza dentro de seus princípios e diretrizes, a integralidade de assistência, que é entendida como "conjunto articulado e contínuo das ações e serviços preventivos e curativos, individuais e coletivos, exigido para cada caso em todos os níveis de complexidade do sistema" (Lei 8.080/90).

Os níveis de complexidade do sistema estão dispostos em três, sendo que, o nível primário está qualificado para atender e resolver os principais problemas que demandam serviços de saúde. Os que não forem resolvidos neste nível deverão ser referenciados para os serviços de maior complexidade tecnológica. O nível secundário, são os centros de especialidades e, no nível terciário de atenção à saúde estão os hospitais de referência.

Todo cidadão tem direito a uma assistência global, onde o profissional de saúde, em questão o enfermeiro, deve ter uma visão holística. Assim sendo, a relação entre o enfermeiro e o paciente deve discorrer de tal forma que sejam considerados os aspectos emocionais, econômicos e culturais, onde o diálogo entre paciente e enfermeiros é primordial. Esta assistência proporciona tanto o bem-estar físico como mental e ambiental, permitindo a atuação do profissional, também na prevenção de doenças, e desta forma, é possível perceber a importância do conhecimento da integralidade, por parte dos profissionais de saúde, na Rede Básica. Diante destas questões, foi estabelecido como objetivo deste estudo conhecer os significados sobre a integralidade por enfermeiros de Unidades de Saúde da cidade de Goiânia, Goiás.

\section{REVISÃO DA LITERATURA}


A Lei Orgânica da Saúde, em seu artigo 198, II, estabelece prioridades para as atividades preventivas, coerentemente com o mandamento enunciado no artigo 196 que diz respeito ao combate às causas da doença e de outros agravos. Constitucionalmente, o SUS é organizado de acordo com as seguintes diretrizes: a descentralização, o atendimento integral, e a participação da comunidade. De acordo com essas diretrizes constitucionais, o SUS obedece aos seguintes princípios: universalidade de acesso aos serviços de saúde em todos os níveis de assistência; integralidade da assistência; preservação da autonomia da pessoa na defesa da sua integridade física e moral; igualdade de assistência; direito à informação; divulgação de informações sobre o potencial dos serviços de saúde e a sua utilização pelo usuário; utilização da epidemiologia para o estabelecimento de prioridades, a alocação de recursos e a orientação programática; participação da comunidade e, descentralização político-administrativa com direção única em cada esfera do governo.

Segundo SANTOS \& CARVALHO (1995, p.77) "a leitura do princípio da integralidade da assistência há de se fazer combinadamente como o princípio da igualdade de assistência (inciso IV). Em primeiro lugar a assistência integral combina de forma harmônica e igualitária, as ações e os serviços de saúde preventivos com as assistências ou curativos. Em segundo lugar a assistência implica, como se enuncia atenção individualizada, ou seja, para cada caso, segundo suas exigências, e em todos os níveis de complexidade".

O conceito de integralidade é um dos pilares a sustentar a criação do Sistema Único de Saúde. Princípio consagrado pela Constituição de 1988, seu cumprimento pode contribuir muito para garantir a qualidade da atenção à saúde e, conseqüentemente, a melhoria da qualidade de vida do usuário que utiliza o serviço do SUS.

Para CAMPOS (2003), o sistema de saúde busca oferecer atualmente a assistência integral através de uma maior articulação das práticas e tecnologias relativas ao conhecimento clínico e epidemiológico. O primeiro desafio na busca do atendimento integral é reestruturar a forma como os distintos estabelecimentos e organizações do setor saúde trabalham ainda até os dias de hoje. A mudança das práticas de saúde deve ocorrer em dois níveis. O primeiro, institucional, da organização e articulação dos serviços de saúde. O segundo, das práticas dos profissionais de saúde, no qual a equipe de saúde é determinante do processo de estruturação das práticas integrais à saúde.

Outro aspecto ligado à integralidade refere-se à garantia de acesso do indivíduo, aos três níveis de atenção à saúde, nível primário, nível secundário e nível terciário. A idéia de que níveis de complexidade estejam relacionados diretamente com menor ou maior grau de especialização leva à idéia de que a atenção primária à saúde apresenta menor grau de dificuldade ou exige menor grau de conhecimento ou habilitação. CAMPOS (2003), afirma que isso é um equívoco, pois o nível de complexidade mais básico do sistema está relacionado com a necessidade de conhecimentos mais abrangentes, enquanto os níveis secundário e terciário são mais específicos ou parcelados/especializados, e usam intensivamente procedimentos baseados em aparelhos e exames. No nível primário são utilizadas intervenções com enfoque preventivo, comunitário e coletivo, destinadas a atender aos problemas mais comuns da população.

$\mathrm{Na}$ integralidade o modo de entender e abordar o indivíduo baseia-se na teoria holística, integral. Para o holismo o homem é um ser indivisível e não pode ser explicado por seus aspectos físico, psicológico e social, ou seja, avaliados separadamente.

A garantia do princípio da integralidade implica dotar o sistema de condições relacionadas às diversas fases da atenção à saúde, ao processo de cuidar, ao relacionamento do profissional de saúde com os pacientes. Indivíduos e coletividades devem dispor de um atendimento organizado, diversificado e humano. Esse princípio, portanto, não exclui nenhuma das possibilidades de se promover, prevenir e restaurar a saúde e reabilitar os indivíduos. Para se alcançar a integralidade no sistema de saúde faz-se necessário que os gestores municipais, estaduais e federais passem a dar prioridade a este princípio.

De acordo com GIOVANELLA et al (2000), os sistemas integrais de saúde deveriam atender a algumas premissas básicas, quais sejam: a primazia das ações de promoção e prevenção; a garantia de atenção nos três níveis de complexidade da assistência médica; a articulação das ações de promoção, prevenção, cura e recuperação; a abordagem integral do indivíduo e famílias.

O Ministério da Saúde e o Ministério da Educação realizaram um Seminário Nacional sobre o Aprender SUS em que apresentaram sugestões de mudanças nas graduações da área da saúde (BRASIL, 2004). Destaca que a integralidade da atenção à saúde supõe, entre outros aspectos, a ampliação e o desenvolvimento da dimensão cuidadora no trabalho dos profissionais para que se tornem mais responsáveis pelos resultados das práticas de atenção, mais capazes de acolhimento, de vínculos com os usuários das ações e serviço de saúde e, também, mais sensíveis às dimensões do processo saúde /doença não inscritas nos âmbitos tradicionais da epidemiologia ou da terapêutica.

Ainda destacando os objetivos do Seminário Aprender SUS a atenção integral à saúde implica ampliação dos referenciais com que cada profissional de saúde trabalha na construção de seu repertório de 
compreensão e ação e, ao mesmo tempo, o reconhecimento da limitação da ação uniprofissional para dar conta das necessidades de saúde dos indivíduos e das populações. Destaca-se que a atenção integral implica em mudanças nas relações de poder entre profissionais de saúde (para que efetivamente constituam equipe multiprofissional) e entre profissionais de saúde e usuários (para que se desenvolva efetivamente a autonomia dos usuários).

A integralidade dispõe de práticas inovadoras em todos os espaços de atenção a saúde e em diferentes cenários. Nesse sentido, a integralidade requer a implementação clara e precisa de uma formação para as competências gerais necessárias a todos os profissionais de saúde, tendo em vista uma prática de qualidade, qualquer que seja seu local e área de atuação, que desenvolva a capacidade de análise crítica de contextos e que problematize saberes e processos de educação permanente, no desenvolvimento das competências especificas de cada trabalho.

Segundo PINHEIRO (2003), a integralidade do cuidado na atenção às pessoas deve ser entendida como um princípio norteador de uma política de Estado para a Saúde - o SUS - que tem no campo das práticas um espaço privilegiado para a materialização da saúde como direito e como serviço. Isso significa dizer que a Integralidade, como eixo norteador de uma política, deverá ser construída cotidianamente, por permanentes interações democráticas dos atores, pautada por valores emancipatórios fundados na garantia da autonomia, no exercício da solidariedade e no reconhecimento da liberdade de escolha do cuidado e da saúde que se deseja obter.

Concordamos com a declaração de Regina Henriques, enfermeira e ex-diretora da Universidade Estadual do Rio de Janeiro, de que a natureza do trabalho da enfermagem é dialogar com o paciente o tempo inteiro, e que para isso, é necessário buscar formas de dialogar com a pessoa de quem está se cuidando. Na prática da enfermagem, o cuidado mais humano é um elemento muito presente. A enfermagem teve também, por muito tempo, os cursos marcados pela questão da tecnologia e da ciência. Então, se por um lado, os enfermeiros têm a facilidade do contato direto, por outro, algumas coisas ficaram sem aprofundamento na história. Ao trazer a integralidade como eixo de discussão, essas questões têm vindo à tona. Assim, vemos a necessidade de discutir entre nossos pares para desmistificar algumas coisas, compreender porque o enfermeiro, que tanto fala do cuidado integral e humanizado, afasta-se do paciente e envolve-se com outras atividades cada vez mais administrativas.

\section{CAMINHO METODOLÓGICO}

O trabalho realizado foi um estudo descritivo com abordagem qualitativa que busca o desvelar do fenômeno por si mesmo, na sua essência. Sua ênfase está na compreensão do que se deseja conhecer, e não em teorias explicativas. Optamos por esta abordagem por acreditar ser ela a que melhor atende o nosso objeto de estudo. Segundo MARTINS \& BICUDO (1994, p.23), a abordagem qualitativa "(...) busca uma compreensão particular daquilo que estuda (...) não se preocupa com generalizações, princípios e leis (...) o foco de sua atenção é centralizado no especifico, no peculiar, na individualidade, almejando sempre a compreensão e não as explicações dos fenômenos estudados".

Por meio de relatos de enfermeiras que já vivenciaram no cotidiano o fenômeno em questão se deu a compreensão do mesmo.

Conforme MARTINS \& BICUDO (1994), as descrições para experiências que os sujeitos viveram, estão nelas as essências do que se busca conhecer e a intencionalidade do sujeito. A essência do fenômeno não é o fim da análise, mas o meio pelo qual se pode trazer à luz o que as relações vividas apresentam de essenciais. Desta forma, o objetivo da pesquisa buscou descrever a natureza da experiência vivida.

Este projeto teve início após a aprovação do Comitê de Ética e Pesquisa da Universidade Católica de Goiás (CAAE no 0063.0.168.000-05) e contém relatos de Enfermeiras que atuam há mais de um ano na profissão e em uma das Unidades Básicas de Saúde que compõe o Distrito Sanitário da Região Noroeste de Goiânia, ou seja: CAIS Finsocial, CAIS Jardim Curitiba e Maternidade Nascer Cidadão, que se dispôs a colaborar voluntariamente com a pesquisa.

As informações coletadas foram realizadas pelas pesquisadoras, por meio de entrevista semiestruturada, gravadas em fita cassete, com a prévia autorização do sujeito, que assinou o termo de consentimento e livre esclarecido (Anexo II). Foi mantido o sigilo e o anonimato dos participantes, conforme a Resolução 196/96 do Conselho Nacional de Saúde (BRASIL, 1996). Encerramos a coleta de dados no momento em que percebermos a saturação por repetições e convergências do conteúdo investigado.

Em busca do desvelar do fenômeno formulamos duas questões norteadoras para que o indivíduo revelasse seu pensar:

1. Fale para nós sobre integralidade.

2. Em que momento do seu cuidar cotidianamente você identifica a integralidade?

\section{O DESVELAR DO FENÔMENO}

\section{Renomeação dos sujeitos}


A renomeação dos sujeitos foi realizada baseada na observação das características pessoais apresentadas pelas enfermeiras, no momento das entrevistas e por meio da análise dos seus relatos.

Avaliando separadamente o comportamento e a forma de expressão de cada enfermeira, selecionamos alguns substantivos derivados de adjetivos que mais se assemelham e refletem as características pessoais de maior destaque.

Os substantivos atribuídos às enfermeiras são identificados como: amizade, sensibilidade, parceria, sinceridade, gentileza, indiferença, comunicação, compreensão e equívoco.

\section{INTEGRALIDADE: entre o conhecer e o aplicar}

Nesta categoria agrupamos relatos das enfermeiras participantes deste estudo que conhecem, desconhecem e/ou confundem o significado de integralidade, aplicando-os ou não em seu cotidiano. Entendem integralidade, como atender o paciente como um todo, de forma holística e globalizada. Como podemos ler abaixo:

“... nossa integralidade é você está atendendo o paciente como um todo. Você Ver o indivíduo como um todo" $\rightarrow$ Amizade

"Integralidade é ver o doente de forma holística. É vê-lo como pessoa física, espiritual, emocional, social, econômica, vê-lo como um todo. E cuidar dos seus problemas de forma que a gente respeite o todo." $\rightarrow$ Sensibilidade

"Atendimento integral [...] você atende de modo global, globalizado, como o mundo de hoje está globalizado, então o atendimento é globalizado, a gente, pelo menos, a gente está caminhando para isso. Às vezes, existem algumas falhas [...] a gente está buscando atender o usuário, hoje a gente não chama mais de paciente, a gente está buscando atender o usuário de maneira global, tanto do lado psicológico, social, é aspecto integralizado mesmo. Aqui, por exemplo, a gente trabalha o médico, a enfermagem, a psicóloga." $\rightarrow$ Parceria

"A integralidade do paciente, quando ele chega aqui, eu não quero cuidar só daquela ferida, naquele momento. Eu quero vê-lo como um todo. Eu quero ver como ele está na casa dele, até que ponto vai influenciar na cura desse paciente. É muito importante eu ver isso. [...] É justamente ver o paciente como um todo. E no entanto não faz isso. Então fica muito difícil. Você fala as coisas, mas no papel está, mas na hora de você fazer, você não tem condição. $E$ isso deixa você frustrada." $\rightarrow$ Sinceridade
“... não só cuidar daquele aspecto restrito, mas da pessoa como um todo... físico, mental, espiritual." $\rightarrow$ Gentileza

"Integralidade é aquele respeito que nós temos que ter com o paciente, na minha profissão. Vendo que o paciente é a parte principal na nossa relação. Tratar o paciente como um todo, tanto social como psicologicamente."

Indiferença

"Eu entendo integralidade como a visão do todo do paciente. Não só do paciente, mas, qualquer pessoa que... do cliente que você está atendendo ou dos funcionários. [...] é você está enxergando o paciente, cliente, de forma como o todo, não uma parte só. No caso a gente que trabalha aqui na saúde da família, a gente atende o paciente, ele chega aqui com falta de dinheiro, com o marido que bate, com falta de um monte de coisas, carente. Um exame de prevenção que a gente faz, não dá simplesmente pra você chegar, o paciente entra aqui, você colher a prevenção. O que a gente tem que fazer, é realmente, consultar o paciente, ver as necessidades dele, emocionais e tudo mais. Explicar o que é a consulta, pra quê você está fazendo aquilo. [...] Mas acho que a forma de atendimento, a gente tem que atender as pessoas como a gente gostaria de ser atendido. [...] significa que você tem que está vendo todas as partes, as faces desse indivíduo" $\rightarrow$ Comunicação

"o cliente deve ser visto de maneira ampla e integral [...] não basta estarmos focados apenas num sinal e/ou sintoma, abrangência deve ir além disso, buscando estar atentos em todos os níveis socioeconômicos do cliente, pois muitas vezes o cliente precisa, além do tratamento específico, de uma palavra de carinho, uma atenção ou um simples bom dia, principalmente quando lidamos com usuários de baixo poder socioeconômico."

$\rightarrow$ Compreensão

"O cuidar não só pela enfermagem porque as pessoas tem noções de que o cuidar é só do enfermeiro. É o cuidar do psicólogo, o cuidar do médico, o cuidar de toda a equipe multidisciplinar.[...] A gente não tá vendo ele não só com o fator doença, a gente tá vendo a questão sócio-econômica, é na questão cultural." $\rightarrow$ Equívoco

Para PINHEIRO \& MATTOS (2004), o cuidado deve ser apreendido como uma ação integral, que tem significados e sentidos voltados para compreensão de saúde como o direito de ser. É o tratar o respeitar, o acolher, o atender o ser humano em seu sofrimento, em grande medida fruto de sua fragilidade social. A ação integral é também entendida como o "entre-relações" 
de pessoas, ou seja, ação integral como efeitos e repercussões de interações positivas entre usuários, profissionais e instituições, que são traduzidas em atitudes como: tratamento digno e respeitoso, com qualidade, acolhimento e vínculo. Essas ações são inerentes à prática profissional de algumas enfermeiras das instituições pesquisadas, conforme pode ser verificado nos relatos a seguir:

“...nossa integralidade é você estar atendendo o paciente como um todo. Você vê o indivíduo como um todo[...] Eu acho que a todo momento, não só dentro do consultório, mas principalmente quando a gente também trabalha em grupo, faz a visita domiciliar, a gente trabalha essa questão da integralidade. A gente tenta conhecer $o$ paciente na sua casa, na sua moradia, com relações familiares, nas suas condições de trabalho, nas suas condições de moradia e, isso passa também através do atendimento que a gente faz, em grupo com o paciente. A gente tenta trabalhar toda aquela problemática que a gente vivencia na casa [...] você trabalha também as questões que foram levantadas na vivência que a gente tem com esse paciente." $\rightarrow$ Amizade

"Integralidade é ver o doente de forma holística. É vê-lo como pessoa física, espiritual, emocional, social, econômica, vê-lo como um todo. E cuidar dos seus problemas de forma que a gente respeite o todo. [...] Em todos os momentos que eu as minhas orientações, as minhas prescrições de enfermagem, eu penso na integralidade, porque às vezes você está diante de uma pessoa aqui que tem problema a que não é só, é digamos patológico. Ele tem outros problemas espirituais, emocionais, financeiros, e a gente faz as nossas orientações visando tudo isso." $\rightarrow$ Sensibilidade

PINHEIRO \& MATTOS (2004) colocam ainda que a conceituação da integralidade aponte claramente para a dimensão da organização da assistência, sua prática permanece como um objetivo de difícil apreensão e de difícil operacionalização. Isto decorre do fato de que sua aplicação no cotidiano das instituições de saúde esbarra em limites oriundos da "dificuldade de traduzir o conceito de integralidade, de fato, em novas práticas, o que acaba por reduzi-lo a uma soma ou justaposição das ações de cunho coletivo ou preventivo com as de cunho individual curativo".

A frustração vem à tona, por não conseguir aplicar a integralidade no seu cuidar, mesmo tendo conhecimento da mesma. Como relata Sinceridade:
"A integralidade do paciente, quando ele chega aqui, eu não quero cuidar só daquela ferida, naquele momento. Eu quero vê-lo como um todo. Eu quero ver como ele está na casa dele, até que ponto vai influenciar na cura desse paciente. É muito importante eu ver isso. [...] É justamente ver o paciente como um todo. E, no entanto, não faz isso. Então fica muito difícil. Você fala as coisas, mas no papel está, mas na hora de você fazer, você não tem condição. $E$ isso deixa você frustrada".

A integralidade não pode ser percebida como atributo da boa prática biomédica, mas como um atributo que permeia a prática de todos os profissionais de saúde, independente dela se dar no âmbito público ou privado. Deve ser fruto do esforço e confluência dos vários saberes de uma equipe multiprofissional, no espaço concreto e singular dos serviços de saúde.

Segundo PINHEIRO \& MATTOS (2001) são consideradas "integralidade focalizada" aquela que é trabalhada no espaço bem delimitado (focalizado) de um serviço de saúde. O resultado dessa integralidade há de ser o resultado do esforço de cada um dos trabalhadores e da equipe como um todo. Cada atendimento, de cada profissional, deve estar compromissado com a maior integralidade possível, sempre, mas também ser realizado na perspectiva de que a integralidade pretendida só será alcançada como fruto do trabalho solidário da equipe de saúde, com seus múltiplos saberes e práticas. Maior integralidade possível na abordagem de cada profissional, maior integralidade possível como fruto de um trabalho multiprofissional.

Diante disso, concluímos que a integralidade pode estar presente no atendimento individual de cada profissional pertencente à equipe de saúde, no entanto, evidenciamos nos relatos de Parceria e Confusão, uma mistura de conceitos, em que a definição de integralidade é confundida com a de multidiciplinaridade.

"Atendimento integral [...] você atende de modo global, globalizado, como o mundo de hoje está globalizado, então o atendimento é globalizado, a gente, pelo menos, a gente está caminhando prá isso. Às vezes existe algumas falhas [...] a gente está buscando atender o usuário, hoje a gente não chama mais de paciente, a gente está buscando atender o usuário de maneira global, tanto do lado psicológico, social, é aspecto integralizado mesmo. Aqui, por exemplo, a gente trabalha o médico, a enfermagem, a psicóloga. [...]Que o trabalho individual, no consultório, eu acho que ele fica um pouco a desejar" $\rightarrow$ Parceria 
"O cuidar não só pela enfermagem porque as pessoas tem noções de que o cuidar é só do enfermeiro. É o cuidar do psicólogo, o cuidar do médico, o cuidar de toda a equipe multidisciplinar." $\rightarrow$ Equívoco

De acordo com PINHEIRO \& LUZ (2003), a concretização da integralidade não passa, portanto, pela aplicação exclusiva dos saberes disciplinares já existentes, mas pela construção incessante de práticas eficazes. Trata-se de um desafio que tem como horizonte não apenas um êxito técnico, mas um sucesso prático, que se diferencia daquele na medida em que tem de ser remetido explicitamente ao plano das relações.

A integralidade deve fazer parte da filosofia da enfermagem. A valorização da essência do ser humano deve conduzir o pensamento e as ações do enfermeiro, tornando-o capaz de criticar e construir uma realidade mais humana. No entanto, constatamos que a integralidade não é compreendida em toda sua magnitude, por grande parte das entrevistadas. O que nos leva a refletir e questionar a qualidade da assistência prestada aos usuários que procuram os serviços públicos de saúde.

\section{INTEGRALIDADE: o despreparo para lidar com a subjetividade do outro}

As enfermeiras entrevistadas deixaram transparecer em suas falas a adoção ou não da humanização na assistência, relatando seus conhecimentos e experiências vivenciadas no cotidiano. Por meio dos relatos, notamos o envolvimento e respeito com os usuários, entretanto, podemos observar a precária interação e despreparo para lidar com a dimensão subjetiva nas práticas de atenção, por parte de algumas enfermeiras, como descrito nos discursos abaixo:

"Eu acho que a todo o momento, não só dentro do consultório, mas principalmente quando a gente também trabalha em grupo, faz a visita domiciliar, a gente trabalha essa questão da integralidade. A gente tenta conhecer o paciente na sua casa, na sua moradia, com relações familiares, nas suas condições de trabalho, nas suas condições de moradia e, isso passa também através do atendimento que a gente faz, em grupo com o paciente. A gente tenta trabalhar toda aquela problemática que a gente vivencia na casa [...] você trabalha também as questões que foram levantadas na vivência que a gente tem com esse paciente." $\rightarrow$ Amizade

"Sempre, em todos os momentos que eu as minhas orientações, as minhas prescrições de enfermagem, eu penso na integralidade, porque às vezes você está diante de uma pessoa aqui que tem problema a que não é só, é digamos patológico. Ele tem outros problemas espirituais, emocionais, financeiros, e a gente faz as nossas orientações visando tudo isso. [...] Então a gente tem que enxergar o paciente e, como ele pode alcançar a saúde da melhor forma possível, qual o caminho que a gente pode traçar pro paciente da melhor forma possível. Se o paciente, por exemplo, tem diabetes não pode ser emocional? $E$, ou se ele tem a diabetes e a gente passa a dieta e polipídica, muita fruta, muita verdura, ele tem dinheiro pra comprar? Quais tão mais baratas, quais a gente pode está orientando, isso é verificar o paciente de forma integral. É, levar que ele tenha saúde da melhor forma, da maneira mais adequada, na medida da necessidade dele mesmo, não é isso? " $\rightarrow$ Sensibilidade

“... nos trabalhos em grupo que a gente faz [...] eu vejo integralidade nos trabalhos de grupo [...]. Que o trabalho individual, no consultório, eu acho que ele fica um pouco a desejar" $\rightarrow$ Parceria

"Você fala as coisas, mas no papel está, mas na hora de você fazer, você não tem condição. E isso deixa você frustrada. [...] nem no PSF, que está pra fazer isso, ele não faz. Eles acham que não tem tempo, eles acham que agenda as pessoas e não tem condição de atender bem. [...] Se as vezes você chega lá na emergência, tem um paciente que está brigando, que ele quer ser consultado agora. Você olha nele, está cheio de manchas roxa, paciente está chorando, aí você traz ela pra sua sala, você vai conversar com ela, você vai ver que não é isso que ela está precisando. O simples ensinar uma mãe como dá o banho na criança, como amamentar. O carinho que essa amamentação passa pra essa criança. Isso é saber acompanhar esse paciente, não só aqui na fase curativa não, na preventiva. [...] aí você vai ver o paciente mais como um todo, a integralidade por inteiro" $\rightarrow$ Sinceridade

“... em todo momento. É quando eu chego de manhã pra fazer visita pro paciente. [...] No antes, pré ou pós o parto. No momento até daquela abordagem, daquela visita, eu olho a pessoa como um todo. Eu acho que a integralidade tem que tá em todo momento. É o momento que eu posso olhar a pessoa de uma maneira fragmentária. [...] No momento mais específico, mais delicado, no momento do parto mesmo; pré-parto imediato e no parto. Eu acho que é esse o momento que você tem que ter esse olhar de mais integralidade [...] a gente participa junto com o médico [...] dando aquele 
apoio pessoal. É nesse sentido. Não simplesmente ela vai dar a luz, vai terminar, vai estar ali inteira." $\rightarrow$ Gentileza

"Eu atuo com integralidade em todo momento da minha vida. Todo paciente que vem aqui eu respeito muito. [...] Não deixando os problemas de o paciente interferir na minha conduta. [...] Eu tenho que muitas vezes que pôr uma couraça, assim... pra que o paciente traz pra mim, não me afeta. Eu tenho que tratar o paciente como um todo mas, de acordo com o que ele está sentindo. [...] O paciente vem aqui e chora. Quer que eu envolva na vida dele e, eu trato ele como um ser humano, mas, ele lá e eu cá. Vem pra mim com todos seus deveres, todas suas carências mas, eu não posso deixar me influenciar" $\rightarrow$ Indiferença

“... na hora do exame de prevenção, por exemplo. Ou na hora do CD (crescimento e desenvolvimento da criança), que a gente vai fazer aferimento da criança [...] só, por exemplo, a criança chegou aqui com febre. Eu só vou, é... orientar, encaminhar pro medico, falar: não! Vai lá ao médico que ele te passa um anti-térmico. Não é só isso. Tem que ver por trás disso o quê que está acontecendo. [...] realmente é ver a pessoa, todas as faces da pessoa [...] tem que está é orientando, esclarecendo, informando realmente. Mas a gente tem muitos casos de pessoa, não tem realmente o que comer. Isso é um fator dificultador." $\rightarrow$ Comunicação

“... Sempre, sempre, sempre, sempre, chegou o paciente tem que identificar." $\rightarrow$ Equívoco

De acordo com FELDMANN et al (1973), humanizar é tudo que desperta o sentimento de solidariedade humana e concorre para facilitar a circulação do homem no mundo.

MEZOMO (1980), afirma que humanizar é um processo vivencial que permeia toda atividade do local e das pessoas que ali trabalham, dando ao paciente o tratamento que ele merece como pessoa.

Uma prática humanizada em saúde é aquela capaz de oferecer atendimento de qualidade, articulando os avanços tecnológicos com o bom relacionamento; incentivo do diálogo entre os profissionais e com os usuários; vínculo entre profissional e usuário, proporcionando assim, um tratamento digno e respeitoso. Esta prática pode ser notada através do discurso de Compreensão:

“... desde que a gestante chega à Unidade para o pré-natal (não preocupo apenas com a barriga, mas também com necessidades e anseios da gestante), depois durante o trabalho de parto (parturiente é atendida de acordo com as necessidades do momento do trabalho de parto, inclusive com esclarecimento sobre suas dúvidas $e$ anseios) e, finalmente, no puerpério (visão vinculo enfermeiro- puerpera e recém-nascido bem estar e boa evolução)."

Concordamos com BOFF (1998), que um dos aspectos envolvidos no cuidar são os sentimentos de solidariedade, amor, compaixão, honestidade, preocupação e desvelo. O cuidado que humaniza acontece porque somos seres humanos, sentimos afeto, amor (fenômeno cósmico e biológico), são sensíveis e tomamos decisões buscando o equilíbrio. Cuidar implica em sentir afeto, ternura, em acariciar pelo toque, em conviver.

Acreditamos que o cuidado da enfermagem deve ser ético, e por isso pressupõe habilidades técnicas, conhecimento, sensibilidade e experiências entre outros. Tal cuidado é guiado por ações que assiste, oferece suporte e facilita ou melhora sua condição humana de vida. Engloba a saúde em sua integralidade, nos seus aspectos psicobiológicos, espiritual, social e político. Como podemos ver abaixo:

“... porque às vezes você está diante de uma pessoa aqui que tem problema a que não é só, é digamos patológico. Ele tem outros problemas espirituais, emocionais, financeiro, e a gente faz as nossas orientações visando tudo isso. [...] Então a gente tem que enxergar o paciente $e$, como ele pode alcançar a saúde da melhor forma possível, qual o caminho que a gente pode traçar pro paciente da melhor forma possível." $\rightarrow$ Sensibilidade

“... você tem que ter esse olhar de mais integralidade [...] a gente participa junto com o médico [...] dando aquele apoio pessoal. É nesse sentido. Não simplesmente ela vai dar a luz, vai terminar, vai estar ali inteira.." $\rightarrow$ Gentileza

COSTA (2004), afirma que o diálogo humaniza a relação entre indivíduos que são fundamentalmente distintos, permitindo a aproximação e a confiança necessária ao processo da cura.

No encontro do usuário com a equipe de saúde deve ocorrer a conversação, na qual deve prevalecer a capacidade de escuta, de forma a permitir a apreensão das necessidades de saúde, trazida por aquela pessoa que busca o serviço. Estamos certas que o diálogo constitui parte do tratamento cuidadoso e domina uma dimensão decisiva de toda a ação de enfermagem. Sinceridade e Comunicação colocam que:

"Você olha nele, tá cheio de manchas roxa, paciente está chorando, aí você traz ela pra sua 
sala, você vai conversar com ela, você vai ver que não é isso que ela está precisando. [...] Isso é saber acompanhar esse paciente, não só aqui na fase curativa não, na preventiva. [...] aí você vai ver o paciente mais como um todo, a integralidade por inteiro"

"...a criança chegou aqui com febre [...] Tem que ver por trás disso o quê que está acontecendo. [...] realmente é ver a pessoa, todas as faces da pessoa [...] tem que está é orientando, esclarecendo, informando realmente."

Segundo BOFF (2004), um outro aspecto a ser discutido na formação do profissional é a desumanização como mecanismo de defesa dos profissionais. O contato com o sofrimento humano pode gerar ansiedade e, como conseqüência, um afastamento, uma dificuldade de interagir com o sujeito.

Por outra parte, PINHEIRO \& MATTOS (2001), afirmam que a desvalorização, por parte do profissional de saúde, na relação com o paciente, se deve em grande medida à falta de uma formação específica voltada para a comunidade, o que considera fundamental para o estabelecimento do vínculo.

COSTA (2004) enfatiza que a lógica centrada no profissional, na ação curativa e focada na queixa, produza efeitos presentes numa prática de saúde desumanizada, não é possível, contudo, atribuir-lhe uma total responsabilidade na manutenção das condições de precariedade do sistema de atenção à saúde.

Sabemos que formação a acadêmica tem importante contribuição neste contexto, uma vez que, com a existência de um ensino não reducionista e menos fragmentado, seria cada vez mais freqüente a formação de profissionais capazes de apreender de seus pacientes suas necessidades de modo mais integral.

Por meio da fala de Indiferença, podemos evidenciar sua incapacidade de estabelecer uma relação com o outro, estando impossibilitada de tratar com sujeitos, focando-se apenas na doença, optando por um modelo de atenção centrado na relação queixa/conduta.

“...Não deixando os problemas do paciente interferir na minha conduta.[...] Eu tenho que muitas vezes que pôr uma couraça, assim... pra que o paciente traz pra mim, não me afeta. Eu tenho que tratar o paciente como um todo mas, de acordo com o que ele está sentindo. [...] 0 paciente vem aqui e chora. Quer que eu envolva na vida dele e, eu trato ele como um ser humano, mas, ele lá e eu cá. Vem pra mim vem com todos seus deveres, todas suas carências mas, eu não posso deixar me influenciar"
Acerca de tudo que a literatura científica discute sobre a integralidade, inferimos que a noção do todo relacionada à saúde é, portanto, preocupação antiga e afirma que o cuidado do corpo pela ação da enfermagem não é possível sem o simultâneo cuidado da alma. No entanto, nem isso seja o bastante, pois talvez seja até impossível fazê-lo sem o conhecimento do ser na sua integralidade.

\section{CONSIDERAÇÕES FINAIS}

Ao finalizarmos este trabalho percebemos que o nosso aprendizado foi grande, no que diz respeito à compreensão do termo integralidade. O que nos proporcionou uma visão ampliada acerca do tema em questão, uma reflexão sobre nossas práticas e ações como futuras enfermeiras, bem como nos levou a questionar a qualidade da assistência de enfermagem que é oferecida à população, na Rede Básica de Saúde.

Percebemos que há um despreparo por parte das enfermeiras participantes do presente estudo para lidar com a subjetividade do outro e, para estabelecer uma interação satisfatória com o usuário do sistema de saúde. Acreditamos que um dos fatores condicionantes para esta situação, é a existência de um ensino, ainda fragmentado e reducionista, nas faculdades de enfermagem. Um outro fator dificultador é a falta de investimentos, por parte das Unidades de Saúde, na qualificação profissional de seus funcionários, inclusive da equipe de enfermagem; podemos citar ainda, o desinteresse de algumas enfermeiras em manterem-se atualizadas no campo do conhecimento.

A academia deveria proporcionar aos alunos um ensino que contempla a totalidade do cuidado, a humanização no atendimento, destacando a subjetividade e a singularidade do usuário. Acreditamos ainda, que a prática da integralidade deveria ser instituída nas academias, onde a apreensão de termos como vínculo, acolhimento, afetividade e respeito estariam presentes na relação professor-alunodepartamento, facilitando assim, a internalização da integralidade por parte dos alunos e conseqüente reflexão da mesma em suas futuras relações profissionais.

As Unidades de Saúde deveriam promover seminários, debates e incentivar a educação continuada, com a abordagem de temas como integralidade, humanização, dentre outros relacionados a políticas de saúde, a fim de promover o aperfeiçoamento profissional e conseqüentemente a melhora da assistência prestada aos usuários da Rede Básica.

Ainda que se exista uma academia capacitada para oferecer um ensino livre de fragmentações e, 
Unidades de Saúde empenhadas na promoção da capacitação profissional, a qualidade do atendimento e a assistência integral e humanizada do cuidado não poderia ser garantida, se as enfermeiras não possuírem empatia, compromisso, respeito com os usuários e o interesse em expandir ou adquirir novos conhecimentos.

Sugerimos que a integralidade seja algo como um ideal de objetividade para investigação científica, difícil de ser plenamente atingido, mas do qual constantemente, buscamos nos aproximar.

\section{REFERÊNCIAS BIBLIOGRÁFICAS}

BOFF, L. O despertar da águia. O diabólico e o simbólico na construção da realidade. Petrópolis: Vozes, 1998.

BOFF, L. Saber cuidar: Ética do humano-compaixão pela terra. Petrópolis: Vozes, 2004.

BRASIL. Diretrizes e normas regulamentadoras de pesquisas em seres humanos. Resolução n.196 de 10 de outubro de 1996. Ministério da Saúde/ Conselho Nacional de Saúde. Brasília, 1996.

BRASIL. MINISTÉRIO DA SAÚDE. Aprender SUS e as mudanças na graduação na saúde. In: Seminário Nacional. Brasília. 2004.

CAMPOS, C.E.A. O desafio da integralidade segundo as perspectivas da vigilância da saúde e da saúde da família.2003. [online] Disponível em: http://www.scielo.br/pdf/csc/v8n2/a18v08n2.pdf\#search $=\% 22 \% 220 \% 20$ desafio $\% 20$ da $\% 20$ integralidade $\% 20$ se gundo $\% 20$ as $\% 20$ perspectivas $\% 20 \mathrm{da} \% 20$ vigil\%C3\%A2 ncia\%20da\%20sa\%C3\%BAde \%20e\%20da\%20sa\%C3 \%BAde\%20da\%20fam\%C3\%ADlia\%22\%22. [Acesso em 18 mar. 2005].

COSTA, A.M. Integralidade na atenção e no cuidado a saúde. Saúde e Sociedade. [online] v. 13, n. 3, 2004. Disponível

em:

http://www.apsp.org.br/saudesociedade/XIII 3/integralid ade.htm. [Acesso em: 20 set. 2005].

FELDMANN, M.A. et al. Aspectos de humanização do serviço de enfermagem no hospital do servidor público estadual de São Paulo. Rev. Bras. Enfermagem, v. 5, n. 6, p. 514-24, 1973.

GIOVANELLA et al. Integralidade da atenção em sistemas municipais de saúde: metodologia de avaliação e intervenção. Relatório de pesquisa, Rio de Janeiro. ENSP/FIOCRUZ, Rio de Janeiro, 2000. mimeo. MARTINS, J.; BICUDO, M.A.. A pesquisa em psicologia: fundamentos e recursos básicos. 2.ed. São Paulo: Ed. Moraes, 1994. p. 23-24.

MENDES, E.V. As políticas de saúde no Brasil nos anos 80: a conformação da reforma sanitária e a construção da hegemonia do projeto neoliberal. In: Distrito Sanitário - O processo social de uma mudança das práticas sanitárias do Sistema Único de Saúde. 4. ed. São Paulo - Rio de Janeiro: Hucitec, 1999. Cap. 1 p.19-91.

MEZOMO, J.A. O que é humanização no hospital? Circular 02/80. In: Congresso Brasileiro de Humanização do Hospital e da Saúde, 1, São Paulo, 1980.

PINHEIRO, R.; MATTOS, R.A. Os sentidos da integralidade na atenção e no cuidado à saúde. Rio de janeiro: UERJ, IMS - ABRASCO, 2001.

PINHEIRO, R. Atenção à Saúde: Universalização/focalização, a enfermagem e a atenção básica ambulatorial - um olhar a partir das práticas de integralidade em saúde. Trabalho apresentado no $55^{\circ}$ CBEN. Rio de Janeiro, 2003.

PINHEIRO, R.; LUZ, M.T. Práticas eficazes versus modelos ideais: ação e pensamento na construção da integralidade. In: PINHEIRO, R.; MATTOS, R.A. (Org). Construção da integralidade: cotidiano, saberes, práticas em saúde. Rio de Janeiro: IMS/UERJ, 2003.

PINHEIRO, R.; MATTOS, R.A. As fronteiras da integralidade. Rio de Janeiro: Hucitec-ABRASCO, 2004. PINHEIRO, R.; MATTOS, R.A. Construção da integralidade: cotidiano, saberes e práticas em saúde. Rio de janeiro: UERJ, IMS - ABRASCO, 2003.

SANTOS, G.I.C.L.; CARVALHO, L. Lei 8080/90. In: Sistema Único de Saúde - Comentários a Lei Orgânica da Saúde. 2.ed.São Paulo: Ed. Hucitec Ltda, 1995. cap 1. p. $47-219$

Artigo recebido em 21/03/2006

Publicação aprovada em 30/04/2006 